\title{
Surgical management of necrotizing fasciitis due to odontogenic infection with sepsis: a case report
}

\author{
Saka S. Nugroho, ${ }^{*}$ Endang Syamsudin, Andri Hardianto, \\ Lucky Riawan
}

Objective: To perform surgical operation on necrotizing fasciitis due toodontegenic infection with sepsis.

Methods: In this case an odontogenic infection was accompanied by a large open wound on the face and sepsis. Patient was hospitalized in the Dr. Hasan Sadikin General Hospital. Management of this patientin the emergency room were administration of appropriate broad-spectrum empiric antibiotic, incision, pus drainage and extraction of the infected tooth, followed by fluid resuscitation with strict observation. Surgical debridement was then performed.
Results: After being treated for 12 days the patient's condition improved. We planned closure of defects of the facial area, but the patient refused.

Conclusion: Necrotizing fasciitis is an uncommon butpotentially lethal condition associated with high rates of morbidity and mortality. Early diagnosis coupled with emergent surgical debridement, appropriatebroad spectrum empiric antibiotic treatment and a multidisciplinary team approach is essential for successful treatment.
Department of Oral and Maxillofacial Surgery, Faculty of Dentistry, Padjadjaran University / Dr. Hasan Sadikin General Hospital. Bandung, Indonesia
*Correspondence to: Saka Setiono Nugroho, Department of Oral and Maxillofacial Surgery, Faculty of Dentistry, Padjadjaran University / Dr. Hasan Sadikin General Hospital. Bandung, Indonesia sakasetiononugroho@yahoo.co.id

Received 20 August 2016 Revised 21 August 2016 Accepted 03 January 2017 Available online 01 April 2017

Keywords: Necrotizing fasciitis, Odontogenic infections

Cite this Article: Nugroho SS, Syamsudin E, Hardianto A, Riawan L. 2017. Surgical management of necrotizing fasciitis due to odontogenic infection with sepsis: A case report. Journal of Dentomaxillofacial Science 2(1): 54-57. D01:10.15562/jdmfs.v2i1.455

\section{Introduction}

Necrotizing fasciitis is an aggressive infection that affects the superficial fascia with undermining of the overlying soft tissue. The process usually occurs in the fascia of the trunk and extremities but can be seen in the maxillofacial region. The disease usually occurs in patient who are chronically debilitated, those with diabetes mellitus or in patient with small-vessel disease. Various terms including hospital gangrene, gangrenous erysipelas, hemolytic streptococcal gangrene, have been used to describe this disorder. ${ }^{1}$

We report a case of necrotizing fasciitis due to odontogenic infection with sepsis. Early diagnosis combined with emergent surgical debridement, appropriate broad-spectrum empiric antibiotic treatment and a multidisciplinary team approach are essential for successful treatment of necrotizing fasciitis. $^{2}$

\section{Case Report}

A 51-year-old female patient came to the emergency department of Dr. Hasan Sadikin General Hospital complained redness and swelling in the right cheek with rapid breakdown of skin and pus. About 1 month before admission, the patient felt pain onher first inferior right molar tooth. A week later, inferior right submandibular swelling appeared, the patient checked herself to general practitioner in Buahbatu clinic and received 4 kinds of medicine (patients forgot the name) but the condition did not improve and patient felt swelling became larger and extended to the cheek accompanied with fever. Patient then checked to another general practitioner, and received medicine (patient forgot the name and type of medicine). Because the patient's condition did not improve, 3 days before admission, the patient went to another general practitioner for treatment, and then referred to the Ujung Berung Hospital. In the Ujung Berung Hospital, she was initially administered the injection of ketoro-lac and blood tests in the laboratory and then the patient was transferred to the emergency departement of Dr. Hasan Sadikin General Hospital. Patient complained difficulty of eating. The patient has a history of uncontrolled diabetes mellitus (last controlled 2 months ago) and hypertension.

On physical examination, the patient looked ill with signs of severe sepsis, blood pressure of 100/70 $\mathrm{mm} \mathrm{Hg}$, respiratory rate of $25 \mathrm{bpm}$, heart rate of $95 \mathrm{bpm}$, and temperature $36.5^{\circ} \mathrm{C}$. On extraoral examination, there were asymmetrical face with buccal swelling extended into the right submandibular, right periorbital, right retroauricular and right temporal region. On palpation, marked tender edema, painful on pressure, hyperemia, feverish 


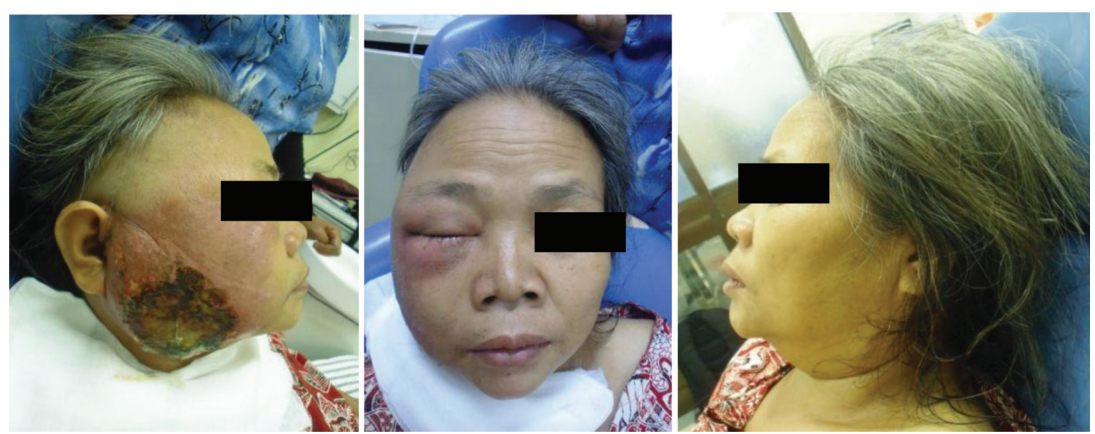

Figure 1 Patient's profile

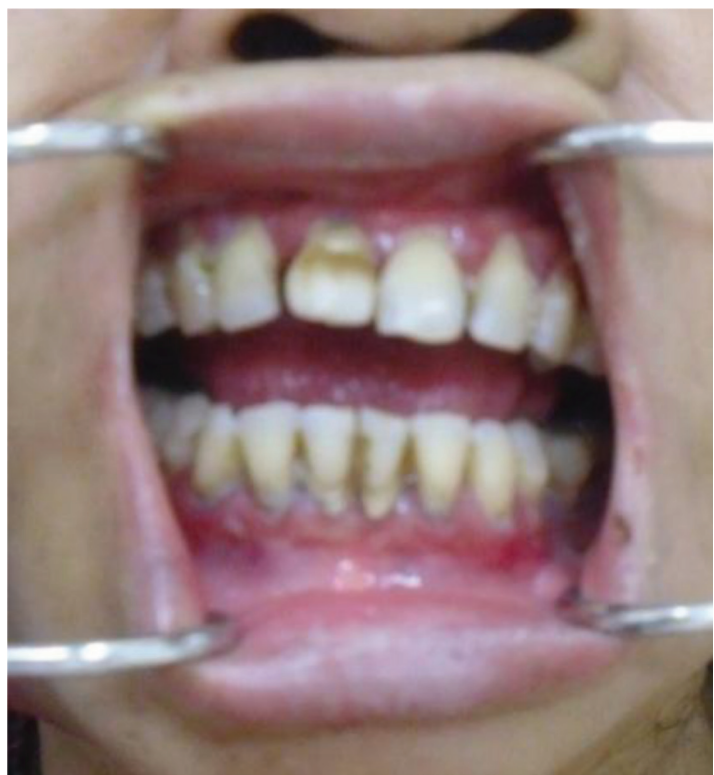

Figure 2 Intra oral

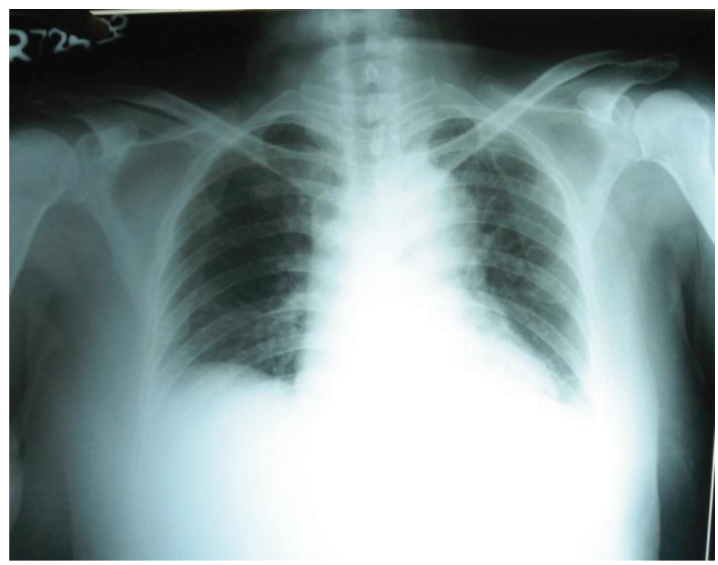

Figure 3 Chest X-rays

and fluctuative. The patient's right ear lobe was lifted. On examination of the eyes, appeared icteric sclera with non-anemic conjunctiva. The right submandibular lymph nodes could not be assessed, while in the left submandibular palpable and painful. On the right submandibular region appeared fistula formation around the necrotic tissue along with pus discharge spontaneously figure 1 .

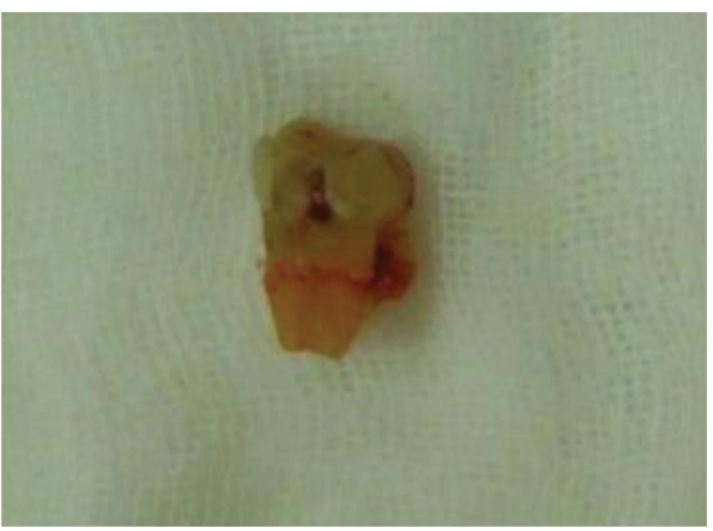

Figure 4 Source of infection tooth

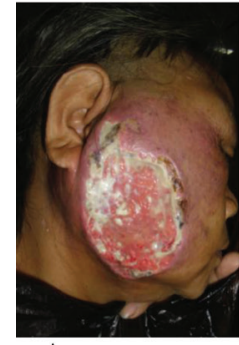

A

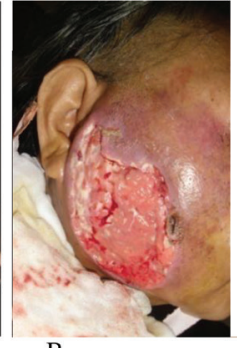

B

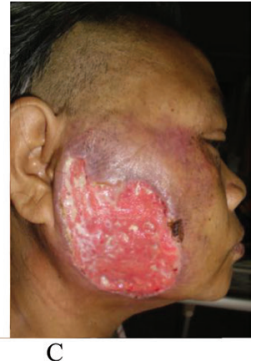

C
Figure 5 A. Day 4; B. Day 6; C. Day 10

were within normal range but gingiva appeared edema and hyperemia. Patient's tonsil could not be assessed because of mouth opening limitation, approximately $1 \mathrm{~cm}$. On examination of the teeth,

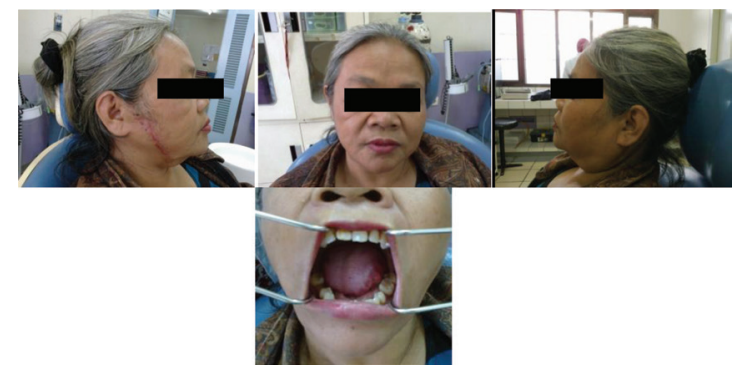

Figure $6 \quad 1$ year

On intra-oral examination, lip, vestibulum, mouth floor, buccal mucosa, tongue and palate founded pulp necrosis in the first inferior right molar tooth. Oral hygiene was very poor with plaque and calculus deposited in the entire region of the maxillary and mandibular teeth figure 2 .

Laboratory work showed leukocytosis, increased lactate level, hiperuremic, hyponatremic, hypercalemic and high glucose level. Blood gas analysis showed respiratoric alkalosis, low $\mathrm{CO} 2$ pressure indicating hypoventilation. CXR indicated absence of active pulmonary tuberculosis, and cardiomegaly figure 3.

Patient was diagnosed sepsis with necrotizing fasciitis due to right buccal abscess extended to 
the right submandibular, right retroauricular, right infraorbital and right temporal region with type 2 diabetes mellitus and neuropathy complications. The patient was then consulted to Internal Medicine department due to high glucose level of $470 \mathrm{mg} / \mathrm{dL}$, before underwent necrotomy debridement and source control. Further advices from Internal Medicine department suggested bed rest, liquid diet via NGT low salt DM $1500 \mathrm{kcal} /$ day, $1 \mathrm{~g}$ protein $/ \mathrm{kg} /$ day, carbohydrate:fat $=60 \%: 40 \%$, infusion of $\mathrm{NaCl} 0.9 \%$ in $2000 \mathrm{cc} / 24 \mathrm{hr}$, novorapid insulin subcutan administration 6-6-6 unit, checked pus culture resistance, blood bulyon culture examination, $\mathrm{KCl} 25 \mathrm{mEq}$ in $500 \mathrm{cc} \mathrm{RL}$, lipid profile examination, uric acid, sodium, potassium and dag curve. Debridement and antibiotics in accordance with plan department of oral and maxillofacial surgery, accompanied by observation of vital signs.

In this emergency unit Department of Oral and Maxillofacial Surgery, the patient was administered antibiotics ceftriaxone $1 \mathrm{~g}$, metronidazole $500 \mathrm{mg}$, ketorolac 1 ampoule and ranitidine 1 ampoule intravenously. Extraction of first inferior right molar tooth was performed to eliminate the source of infection and intra oral drainage figure 4 . Further examination of bacterial culture and drug sensitivity was tested.

Patient then hospitalized and administered liquid diet via NGT low salt DM $1500 \mathrm{kcal} /$ day, $1 \mathrm{~g}$ protein $/ \mathrm{kg} /$ day, carbohydrate:fat $=60 \%: 40 \%$. Wound was treated with gauze, compressed and moist replacement of $\mathrm{NaCl} 0.9 \%$ and povidoneiodine.

From resistance culture examination grew Klebsiellapneumoniae which was sensitive to amikacin, amoxycillin-Clav, cefepime, cefotaxime, ceftazidime, ceftriaxone, ciprofloxacin, cotrimoxazole, gentamycin, imipenem, levofloxacin, meropenem, piperacillintazobactam and tigecyclin. Administration of antibiotic ceftriaxone was appropriate with culture result and patient's condition improved, indicated by decreased level of leukocytes compared to first time came to the hospital and the injuries on the cheek region began to dry with reduced pus production figure 5 .

On day 10, general condition improved as indicated by blood pressure $130 / 90 \mathrm{~mm} \mathrm{Hg}$, heart rate $65 \mathrm{bpm}$, temperature $36.2^{\circ} \mathrm{C}$, and respiratory rate 16 minute. On day 12 , signs of infection were gone and no pus found in the wound, the patient was referred to Plastic Surgery department to plan closure of large defects in the cheek region figure 6.

\section{Discussion}

Necrotizing fasciitis is an aggressive bacterial infection of subcutaneous tissue and fascia.
Although it usually presents in the abdominal wall and extremities, there are several reportedcases of necrotizing fasciitis in the head and neck. The incidence is approximately 4 of 1000 cases of necrotizing fasciitis per year. When necrotizing infections involve the head and neck, it is termed craniocervical necrotizing fasciitis (CCNF) and is associated with significant morbidity and mortality usually due to septic shock, disseminated intravascular coagulation (DIC) and organ failure. ${ }^{3}$

In the prehyperbaric oxygen (pre-HBO) era, standard of care included early recognition of the disease, aggressive antibiotic treatment and repetitive surgical debridement. ${ }^{3}$

The clinical manifestations usually begin rather quiescently, the affected area becomes swollen and erythematous and the patient has a low-grade fever. The site deteriorates rapidly with sudden pain, worsening of the erythema, edema and generalized toxicity. As the disease progresses, the pain subsides as cutaneous nerves become necrotic and anesthesia of the area may occur. The skin overlying the infected fascia becomes dusky with purple mottling. Gas may form under the skin, which may be palpable. If the edges of the affected tissue are probed at this stage, the instrument passes into the plane that the infection is creating between the fascia and the overlying skin. Bullae form as the skin begins to necrose as a result of thrombosis of nutrient vessels as they pass through areas of involved fascia. Frank gangrene of the skin eventually occurs with sloughing of the skin, exposing the underlying necrotizing fascia and subcutaneous fat. ${ }^{4-7}$

Systemic manifestations include signs of sepsis, hemolysis and intravascular volume depletion. The patient has high fever, tachycardia, apathy, weakness and nausea. Anemia, jaundice and hemoglobinuria occur as a result of bacterially induced hemolysis. The patient is hypotensive with decreased skin turgor as a result of fluid losses caused by diaphoresis and extracellular fluid accumulation in the infected site. The overall mortality rate of necrotizing fasciitis is approximately, $30 \%$. however, if the diagnosis is made promptly and treatment is begun early in the disease course, death occurs much more rarely. ${ }^{8}$

Although necrotizing fasciitis historically was thought to be caused by hemolytic streptococci and S. aureus, modern culture techniques have revealed that anaerobes usually are present in the wound. In addition, gram-negative bacteria frequently are present. Therefore early culturing of areas involved by the infection is important to help guide therapy. ${ }^{4}$

Therapy of necrotizing fasciitis involves management of both the local and systemic problems. Laboratory evaluations of hematocrit, started. 
A central venous serum electrolyte levels, including calcium and myoglobin, should be made. Blood for culturing should be obtained before antibiotic therapy is line is helpful to allow determination of intravascular volume and rapid administration of crystalloids. The patient should be taken to the operating suite quickly to begin debridement. Surgery usually involves opening the infected planes widely, resecting frankly necrotic tissue and packing the area under the undermined skin loosely with gauze. Daily debridements then are started to continue to remove any devitalized tissue. ${ }^{6}$ Frozen-section biopsies can assist in guiding resection. ${ }^{9}$

High doses of intravenous antibiotics should be started empirically with agents chosen to cover hemolytic streptococci, staphylococcal organisms, gram-negative bacteria and anaerobes. A combination of penicillin, clindamycin and an aminoglycoside should be effective until the results of culture and sensitivity testing allow a more specific antibiotic regimen. ${ }^{5}$ Use of frozensection biopsy of suspected necrotizing fasciitis is a valuable technique for more rapid diagnosis of this disorder. ${ }^{10}$ Some investigators have reported that hyperbaric oxygen treatment has a favorable effect on the diseased tissue. ${ }^{5}$ Once the infection has resolved, the overlying skin eventually begins to adhere to the underlying fascia and any areas of skin loss as a result of gangrene can be grafted temporarily with porcine skin or grafted permanently with meshed autogeneic skin. Punch biopsies to quantitate tissue bacterial counts can be used before grafting. The graft should not proceed until fewer than $10^{5}$ bacteria per gram of tissue exist. Topical sulfadiazine (sulfadene) can be applied to exposed areas to help clear bacteria. ${ }^{11}$

\section{Conclusion}

Necrotizing fasciitis is an uncommon but potentially lethal condition associated with high rates of morbidity and mortality. Immunodeficiency, multiple medical comorbidities and intravenous drug abuse have been implicated as risk factors. A high index of suspicion is required since a patient's initially benign clinical condition can rapidly deteriorate with the development of sepsis, multiple organ failure and death. Early diagnosis coupled with emergent surgical debridement, appropriate broad-spectrum empiric antibiotic treatment, and a multidisciplinary team approach is essential for successful treatment. ${ }^{2}$

\section{Conflict of Interest}

The authors report no conflict of interest

\section{References}

1. Stoneback JW, Hak DJ. Diagnosis and management of necrotizing fasciitis. Orthop J 2011;34: 196-202.

2. Mao JC, Carron MA, Fountain KR, et al. Craniocervical necrotizing fasciitis with and without thoracic extension: management strategies and outcome. Am J Otolaryngol 2009;30: 17-23.

3. Gaukroger MC. Cervicofacial necrotizing fasciitis. Br J Oral Maxillofacial Surgery. Infections of Soft Tissues of the Maxillofacial and Neck Regions. In Topazian RG et al. Editors. Oral and Maxillofacial Infection. 4th Ed. Philadelphia: WB Saunders Company; 2002. p. 303-305.

4. Krespi RP, Lawson W, Blaugrund SM, et al. Massive necrotizing infection of the neck, head neck surgery. In Topazian RG et al. Editors. Infections of soft tissues of the maxillofacial and neck regions. Oral and Maxillofacial Infection. 4th Ed. Philadelphia: WB Saunders Company; 2002. p. 303-305.

5. Rapoport Y, Himelfarb MZ, Zikk D, et al. Cervical necrotizing fasciitis of Odontogenic origin, Oral Surgery. In Topazian RG et al. Editors. Infections of soft tissues of the Maxillofacial and Neck Regions. Oral and Maxillofacial Infection. 4th Ed. Philadelphia: WB Saunders Company; 2002. p. 303-305.

6. Roser SM. Necrotizing fasciitis, J Oral Surgery. In Topazian RG et al. Editors. Infections of soft tissues of the Maxillofacial and Neck regions. Oral and Maxillofacial Infection. 4th Ed. Philadelphia: WB Saunders Company; 2002. p. 303-305.

7. Chidzonga MM. Necrotizing fasciitis of the cervical region an AIDS patient, J Oral Maxillofacial Surgery. In Topazian RG et al. Editors. Infections of soft tissues of the Maxillofacial and Neck regions. Oral and Maxillofacial Infection. 4th Ed. Philadelphia: WB Saunders Company; 2002. p. 303-305.

8. Andreasen TJ, Green SD, Childers BJ. Massive infectious soft tissue injury, diagnosis and management of necrotizing fasciitis and PurpuraFulminans, PlastReconstr Surgery. In Topazian RG et al. Editors. Infections of soft tissues of the Maxillofacial and Neck regions. Oral and Maxillofacial Infection. 4th Ed. Philadelphia: WB Saunders Company; 2002. p. 303-305.

9. Stamenkovic I. Early recognition of potentially fatal necrotizing fasciitis, $\mathrm{N}$ Engl $\mathrm{J}$ Med In Topazian RG et al Editors. Infections of soft tissues of the Maxillofacial and Neck regions. Oral and Maxillofacial Infection. 4th Edition. Philadelphia: WB Saunders Company; 2002. p. 303-305.

10. Tovi F. Necrotizing soft tissue infection in the head and neck, Laryngoscope. In Topazian RG et al. Editors. Infections of soft tissues of the Maxillofacial and neck regions. Oral and Maxillofacial infection. 4th Ed. Philadelphia: WB Saunders Company; 2002. p. 303-305.

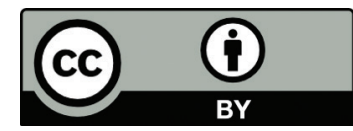

This work is licensed under a Creative Commons Attribution 